\title{
Renovation Measures for Energy-saving Skin of Existing Buildings
}

\author{
Hao Tong ${ }^{1}$, and Kai Chen ${ }^{2 *}$ \\ ${ }^{1}$ School of Civil Engineering, Shandong University, Jinan, Shandong, China \\ ${ }^{2}$ Urban Development Company of China Xiongan Group, Rongcheng, Baoding, Hebei Province, China
}

\begin{abstract}
As an important part of internal and external connections, the building skin can not only beautify the appearance of the building, but also improve the energy-saving performance of the building. This article aims to sort out the specific measures of skin energy-saving renovation from three aspects: the renovation of the peripheral protection structure, the energy-saving renovation of windows and the addition of shading measures, and analyses them in combination with typical renovation cases.
\end{abstract}

\section{Introduction}

The 21st century is an "energy age", in which resource scarcity has become a worldwide problem. A considerable part of energy consumption and carbon emissions come from old buildings with poor thermal performance. Under the influence of a long-term extensive economic growth model, the lack of energy-saving considerations in the process of house construction has led to many existing buildings lacking insulation measures, poor thermal performance, and poor ventilation. Therefore, in view of the huge energy consumption gap of existing buildings in China, it is necessary to renovate old buildings with high energy consumption and low comfort.

Renovation of existing buildings will generally focus on many aspects such as building structural reinforcement, building insulation performance improvement, HVAC equipment renewal, new energy use, and heating and power supply network upgrades [1]. However, in terms of building renovation projects, in order to reduce the impact on the existing functions of the building, most of them will choose to perform energy-saving transformation on the outer skin of the building, which is the most convenient and relatively affordable method. Specifically, the energy-saving transformation and improvement of the building skin mainly involves two aspects: the transformation of the building envelope and the transformation of the building windows.

\section{Reconstruction of the peripheral retaining structure}

\subsection{Increasing building insulation}

Most of the old buildings with a long history of construction often lack the consideration of thermal insulation structure and cannot meet the current building thermal performance standards. There are many types of additional insulation measures for external envelope structure. According to the difference in the location of the insulation layer, they are mainly divided into three ways: sandwich insulation, internal insulation and external insulation. In contrast, sandwich insulation requires placing the insulation layer inside the building wall, which is bound to destroy the original wall of the existing building. Therefore, it is seldom used in renovation projects. The external insulation is better than the internal insulation performance, so external insulation is most commonly selected. The external insulation transformation mainly covers the insulation boards such as EPS, XPS and polyurethane foam plastic boards outside the building structure layer.

This kind of modification can avoid the direct contact between the structural layer of the original building and the outside world, and can effectively "break the bridge for heat insulation" and protect the building structure. However, external insulation is not the only choice for wall reconstruction. In the reconstruction process of part of the cultural and architectural heritage, the influence of insulation layer on the building facade should also be considered. In this situation, only internal insulation can be used, or the combination of internal insulation and external insulation can be used.

\subsection{Double skin structure}

In the case of building with glass curtain wall or air cavity envelope, adding a new glass layer on the outside of the original enclosure structure is always considered as a transformation method. Air chambers are reserved at a distance between the original wall and the new glass wall to buffer the heat exchange between the interior and exterior of the building. The double-layer skin structure can be divided into ventilated type and sealed type according to whether open or not. According to its

*Kai Chen: lytonghao@163.com 
ventilation characteristics, the ventilated double-layer skin structure can be divided into three types: internal circulation, external circulation and double circulation (Fig.1). Among them, the inner circulation is generally completely closed in the outer skin, mainly relying on the internal mechanical ventilation of the building, which is mostly used in cold areas in winter. In the outer circulation, vents are set up on the upper and lower sides of the outer skin to guide the air flow in the air chamber. In the hot summer, users open both upper and lower air vents of the air chamber. Then, the external air enters the air chamber from the lower side vents and flows upward after being heated by light. At the same time, it is discharged from the upper side vents, and the continuous air flow takes away the heat of the building surface. During the winter, users close both vents. The air chamber is filled with air heated by sunlight, which forming a closed "solar room" to achieve thermal insulation (Fig.2).

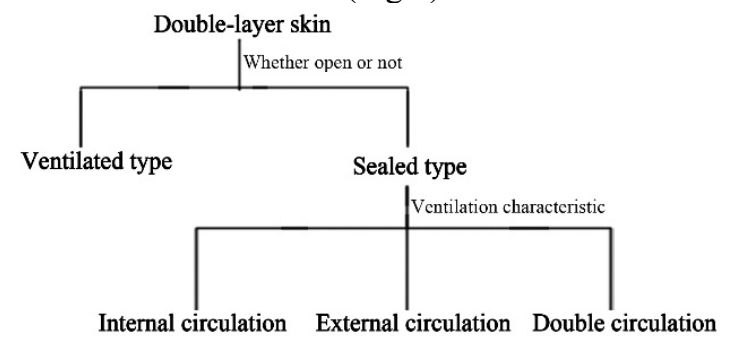

Fig.1. Double-layer skin classification
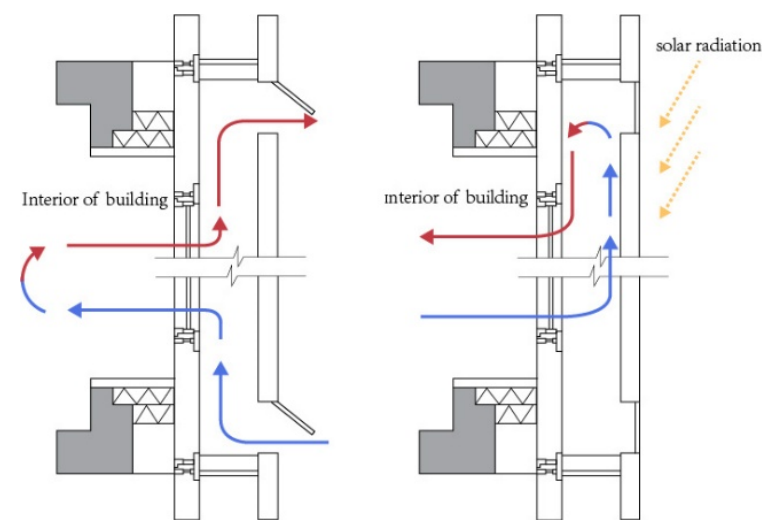

Fig.2. Ventilation of double-layer skin in summer (left) and winter (right)

In contrast, the internal circulation double skin structure needs to borrow the mechanical ventilation system of the building, while the open external circulation double skin structure mainly relies on natural ventilation, with less energy consumption and wider application. For example, in the renovation project of the SUVA office building (Fig.3, Fig.4), Herzog \& Meuron retained the outer protective brick wall of the original building and added a layer of glass curtain wall on the outside of the building [2], thus forming a double-layer skin structure and cushioning the indoor and outdoor heat flow of the building. This design makes full advantage of the thermal insulation and ventilation characteristics of the doublelayer skin, while replacing the old building with the modern building facade style.

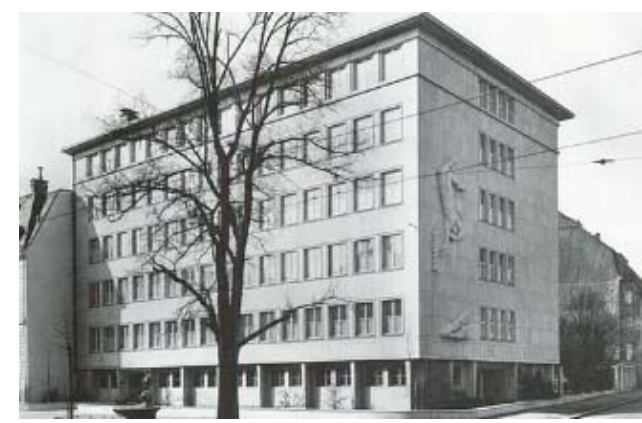

Fig.3. The SUVA office building before renovation

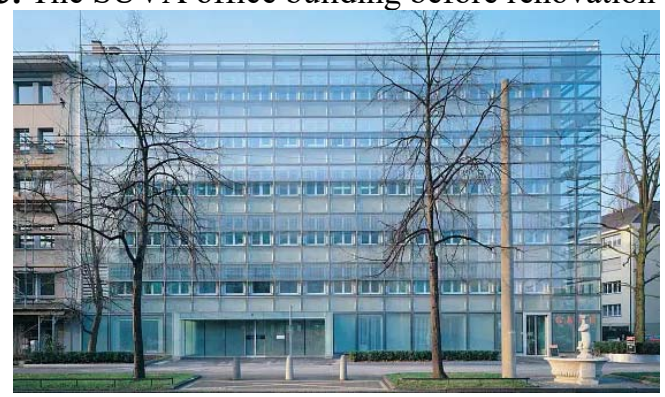

Fig.4. The SUVA office building after renovation

\subsection{Other new energy-saving walls}

The photovoltaic curtain wall (Fig.5) is mainly based on solar photovoltaic power generation technology, combining photovoltaic cells with building components. The early integration of photovoltaic architecture mainly consisted of opaque solar panels arranged on the roof or wall of the building according to the Angle of the sun. After the appearance of semi-transparent film solar cells, they can be combined with glass to be used as building walls envelope components, providing green energy and conforming to modern architectural aesthetics. In the scheme of building renovation, this kind of photovoltaic glass can not only replace the original envelope structure to increase the thermal insulation performance of the building, but also take photovoltaic glass as the outer skin by referring to the transformation method of adding a double-layer skin. On the one hand, solar cells are used to convert light energy; On the other hand, it forms an insulated cavity with the original skin of the building [3].

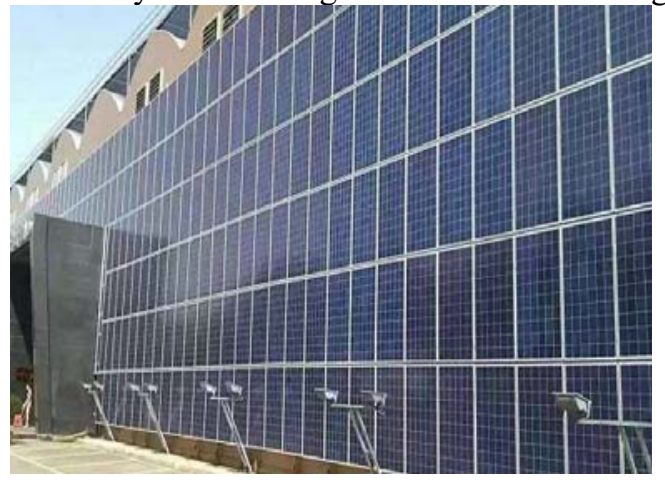

Fig.5. Photovoltaic wall

\section{Window modification}




\subsection{Change building window-wall ratio}

The window-wall ratio parameter of the building should be introduced in the reconstruction of the existing building. The window-wall ratio of a building refers to the ratio of the exterior window area to the wall area of the facade in a certain orientation of the building. Due to the lack of consideration of building energy conservation in the early design of old buildings, the area or position of windows may be improper in pursuit of facade modeling. The thermal conductivity of doors and windows is higher than walls commonly, compare with building periphery protect structure, the energy loss of doors and windows is 4 times of walls. So, the window-wall ratio has a great influence on the energy-saving efficiency of building skin. Windows are a weak link of building heat dissipation, but they introduce the sun's heat during the day, as well as the building's heat-trapping components. At the same time, windows can broaden the view inside the building, so it is not advisable to select larger or smaller window-wall ratio, but to consider the window's orientation, environment and climate, as well as the season to compare and select parameters.

Because our country is located in the northern hemisphere, the sun light comes from the south, for buildings facing south and north, reducing the window-towall ratio of east, west, and north as much as possible while meeting the requirements of use can reduce the total energy consumption of the building's summer air conditioning and winter heating. However, for buildings with windows facing south, due to the infiltration of sunlight, the cooling load of the building in summer will increase, but the heating load in winter will decrease. The annual total energy consumption of the building may decrease first and then increase according to the increase of the building's window-wall ratio, so it is necessary to make a specific comparative analysis according to the case.

\subsection{Change the glass material}

The heat insulation performance of doors and windows is weaker than that of walls. In the process of old building renovation, the heat insulation and airtightness of doors and windows should also be improved. The indexes of energy-saving of glass mainly include heat transfer coefficient $(\mathrm{K})$ and shielding coefficient (SC). The heat transfer coefficient mainly refers to the heat transferred when the difference between the outdoor and indoor building separated by $1 \mathrm{~m}^{2}$ glass is $1^{\circ} \mathrm{C}$ within $1 \mathrm{~h}$. The higher the heat transfer coefficient is, the easier the heat is to conduct on both sides of the glass, which means the worse the heat insulation performance of the glass is. While the shielding coefficient mainly refers to the ratio of the heat transmitted by solar radiation through glass and through $3 \mathrm{~mm}$ ordinary flat glass. The smaller the shading coefficient is, the stronger the performance of glass blocking sunlight radiation is, and the higher the corresponding energy-saving efficiency is. At present, the types of energy-saving glass materials are very diverse and have different energy-saving properties (Table 1).
Among them, the most common ones mainly include lowradiation glass (Low-e glass), heat-absorbing glass, hollow glass and heat-reflecting glass [4]. Heat-absorbing glass is mainly to add colloid colorant inside the glass, so as to absorb solar energy, reduce the penetration of solar heat energy inside the building, and achieve energysaving effect. Both heat-reflecting glass and low-e glass are coated with thin films to change the optical properties of the glass. The difference is that the heat-reflecting glass mainly plates metal or metal oxide on the surface to reduce the shading coefficient of the glass. At the same time, the glass presents different colors due to metal ions, and it can also have certain architectural decoration effect. Low-e glass is also coated glass, but in addition to metal oxides, low-e glass is coated with a silver film that enhances its ability to reflect long-wave infrared rays, thereby reducing the $\mathrm{K}$ value of the glass. Hollow glass is on the basis of other energy-saving glass, two or more layers of glass sealed connection, and fills the inert gas in the middle of the sealed cavity, thereby reducing the heat transfer window. In addition, Shaohua Company of the United States introduced heat-mirror hollow glass material with excellent performance. The heat transfer coefficient $(\mathrm{K})$ of this glass can reach 0.91 , which is much lower than that of ordinary glass, but is not widely available due to its high cost. Generally speaking, the window glass material of old buildings has poor energysaving performance, and most of them need to be replaced. However, due to the consideration of economic factors and glass performance, in renovation projects of the existing building at present, the most common one is to use low-radiation hollow glass with aluminum alloy broken bridge insulation to improve the heat insulation performance of Windows.

Table 1. Energy-saving characteristics of different glass types

\begin{tabular}{|c|c|c|c|c|}
\hline & $\begin{array}{c}\text { Ordinary } \\
\text { glass } \\
(6 \mathrm{~mm})\end{array}$ & $\begin{array}{c}\text { Ordinary } \\
\text { insulating } \\
\text { glass }\end{array}$ & $\begin{array}{c}\text { Low-e } \\
\text { glass }\end{array}$ & $\begin{array}{c}\text { Low-e } \\
\text { (Inert gas) }\end{array}$ \\
\hline $\mathrm{K}$ & 5.7 & 3.1 & 2.4 & 2 \\
\hline $\mathrm{SC}$ & 0.85 & 0.67 & 0.56 & 0.56 \\
\hline
\end{tabular}

\section{Add building shading}

In order to avoid the sunlight radiation entering the interior directly through building periphery protect structure, the building shading is set to prevent the radiation, which can not only reduce the building energy consumption, but also avoid the indoor glare. However, for some old buildings, the shading problem is not considered in the architectural design stage, which affects the building energy consumption and indoor thermal comfort. According to the difference of the position of the shading components in the building, the building shading form can be divided into three types: self-shading, external shading and internal shading. The self-shading of buildings relies on the combination of components or blocks of the building itself to produce shadows, so as to 
achieve the mutual shading effect. However, this method is mainly completed in the early design stage, so it is seldom used in the existing building renovation projects. Both the internal and external shading add shading components to the inside or outside of the building. Internal shading is mainly used to install shading measures such as louvers and rolling curtains in the position of windows. However, since the internal shading components are located in the building interior, part of the radiant heat absorbed and transmitted by them will become the indoor cooling load. In contrast, the external shading measures installed outside the window can directly reflect and absorb part of the sunlight. Only the radiation that penetrates the shading components and windows into the room will generate cooling load. Therefore, its energy efficiency will be higher. At the same time, for the old buildings that need to be transformed, most of their facades need to be renovated and improved. External shading components can save energy and improve the building facade at the same time.

For example, the renovation of Shendu Building in Shanghai has re-added external shading to its facade. The Shendu Building was used as a factory workshop as early as the 20th century and was later transformed into a sixstory office building. In 2009, Shanghai Modern Construction Group carried out the second green renovation of the building (Fig.6). No shading measures were taken into account in the old building before the renovation, and the decorative surface of the building facade was seriously damaged. Therefore, in the process of building energy-saving renovation and upgrading, external shading components should be appropriately added. First of all, the designer added a vertical metal shading net to the south facade of the building, and an inclined $30^{\circ}$ shading net to the east facade. At the same time, the metal visor is also equipped with a rattan plant, which not only increases the shading effect in summer, but also avoids the influence on the solar radiation in winter. The external shading component on the outside reduces the solar radiation in summer, and makes the building facade neat and beautiful. Shading measures were no longer considered on the west side where the auxiliary space is dominant and the north side on the negative side. After the addition of shading components, replacement of doors and windows, planting roofs, and many other energy-saving measures, the monitored energy consumption of Shendu Building is only 66 $\mathrm{kWh} /\left(\mathrm{m}^{2} \mathrm{a}\right)$, which greatly saves energy consumption.

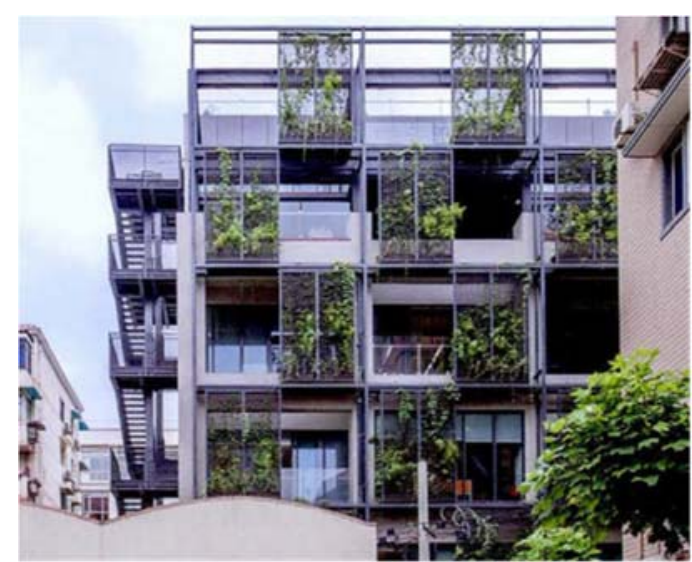

Fig.6. Facade of the renovated Shendu Building

\section{Conclusion}

Under the background of the gradual acceleration of urbanization, more and more attention has been paid to the improvement of functions and energy conservation of existing buildings. As the connection between the indoor and outdoor of the building, the renovation and improvement of the building skin directly affects the energy-saving efficiency and appearance of the building. In a word, the energy-saving renovation and renewal of the existing buildings are mainly carried out in the renovation of the peripheral retaining structure and the renovation of the building windows. Among them, for the reconstruction of the periphery protect structure, the concrete measures such as adding the thermal insulation structure, adding the double-layer skin and replacing the new wall are involved. Renovation measures for windows include changing window-to-wall ratio and replacing glass materials. The designer can choose different renovation plans according to specific project characteristics.

\section{References}

1. Kilburn, Kaye H. Am. J. Med. Sci., 320,4(2000).

2. Editorial Department of Master Series. Herzog and De Meuron's works and thoughts. (China Electric Power Press,2005)

3. T Ebbert. Refurbishment strategies for the technical improvement of office facade. (Delft University of Technology.2010).

4. G. Hua, W. Wang, Y. Zhao. Build. Sci., (2008). 